\title{
Diagnosis and treatment of Rosai-Dorfman disease of the spine: a systematic literature review
}

\author{
Pan-pan Hu, Feng Wei", Xiao-guang Liu and Zhong-jun Liu
}

\begin{abstract}
Purpose: To review and summarize the clinical features, diagnosis, treatment strategies, and prognosis of spinal Rosai-Dorfman disease (RDD).

Methods: RDD is also termed as sinus histiocytosis with massive lymphadenopathy. We searched the databases of PubMed, Elsevier ScienceDirect, SpringerLink, and OVID. The keywords were Rosai-Dorfman disease and spine/central nervous system. Research articles and case reports with accessibility to full texts regarding spinal RDD were eligible for the inclusion. A total of 62 articles were included, and they contained 69 cases. We extracted the information of interest and analyzed them using SPSS statistics package.

Results: The average age was $33.1 \pm 18.3$ years. The ratio of males to females was 1.9/1. Overall, 63 cases presented with spine-related symptoms. A total of 27 cases (39.1\%) had multi-organ lesions, and 12 cases had records of massive lymphadenopathy. Among 47 cases who first manifested spine-related symptoms, 93.6\% were preoperatively misdiagnosed. The disease had a predilection for cervical spine (38.8\%) and thoracic spine (40.3\%). $62.9 \%$ of lesions were dura-based. Surgery remained the mainstream treatment option (78.8\%), with or without adjuvant therapies. Total lesion resection was achieved in $34.8 \%$ of cases. The rate of lesion recurrence/progression was 19.5\%, which was marginally lower for total resection than for non-total resection.

Conclusion: Spinal RDD has no pathognomonic clinical and imaging features. Most cases first present with spinerelevant symptoms. Massive lymphadenopathy is not common, but a tendency for multi-organ involvement should be considered. Spinal RDD has a high recurrence rate; thus, total resection is the treatment of choice. Adjuvant therapies are indicated for multi-organ lesions and residual lesions. A wait and watch strategy is recommended for asymptomatic patients. Herein, a workflow of diagnosis and treatment of the spinal RDD is established.
\end{abstract}

Keywords: Spine, Rosai-Dorfman disease, Literature review, Clinical features, Treatment

\footnotetext{
*Correspondence: puth_wf@163.com

Department of Orthopaedics and Beijing Key Laboratory of Spinal Disease Research, Peking University Third Hospital, No. 49 North Garden Rd, Haidian District, Beijing 100191, China
} 


\section{Background}

Rosai-Dorfman disease (RDD) is a benign disorder, and it is also termed sinus histiocytosis with massive lymphadenopathy [1-3]. Previous etiological studies did not arrive at any firm conclusions. Viral infections, autoimmune conditions, or gene mutations were reported to be related to the development of RDD [3-8]. There were also reports of family cases [9]. Symptomatically, painless neck, axillary, and/or inguinal lymph node enlargement is present in about $80 \%$ of cases. A few patients have fever, weight loss, anemia, and malaise [1, 3]. Over $40 \%$ of cases have extranodal lesions, and the most commonly involved organs are the skin, respiratory tract, orbit, paranasal sinuses, heart, liver and kidney, bone, and central nervous system $[1-3,9,10]$. The disease has a tendency for recurrence and involvement of multiple organs; Mayo clinic has referred to this condition as a histiocytic neoplasm [3].

It is estimated that $0.6-1 \%$ of RDD cases have isolated or concurrent spinal lesions [2, 3, 9-12]. The bone, dura, and cord parenchyma are all nidus candidates. Spinal RDD has no pathognomonic clinical and imaging features. The disorder is often misdiagnosed as infection, spinal tuberculosis, extradural hematoma, meningioma, and other primary or metastatic tumors. It is hardly possible to make the diagnosis unless histopathological and immunohistochemical examinations are performed. There are no consensus guidelines for the treatment of spinal RDD. Treatment regimens are usually prescribed based on personal experience rather than high-level medical evidence. Therefore, we performed a systematic literature review specifically on spinal RDD. This study provides the following referential contents to peers: (a) clinical features of the disease; (b) imaging traits of RDD lesions; (c) summary of current treatment strategies and outcomes; (d) prognosis and possible relevant clinical and therapeutic factors.

\section{Materials and methods Literature search}

A literature search was performed using the following databases: PubMed, Elsevier ScienceDirect, SpringerLink, and OVID. The search strategy for PubMed was presented as follows: Mesh term \#1: (Rosai-Dorfman)OR (sinus histiocytosis with massive lymphadenopathy): ti, $\mathrm{ab}, \mathrm{kw}$; Mesh term \#2: (spine) OR (central nervous system). \#1 AND \#2. We set no limitation regarding the searching fields and date. The language was set as English. All studies retrieved were saved in the software package of EndNote X7. All retrieved literatures were carefully screened. The inclusion criteria were (1) literature regarding the cases with spinal RDD; (2) full texts were available; (3) publication types of research articles and case reports; (4) literature with complete records of patients' demographic information, clinical, and imaging manifestations; (5) references of the eligible articles were also screened. The exclusion criteria were (1) articles in non-English languages; (2) literature with no specific cases recorded; (3) repeated literatures or same cases by same authors in different literatures. The searching, literatures screening, and selecting were performed by $\mathrm{PH}$ and FW independently. The data extraction was also performed independently by the two authors. The results were checked by the other authors. All eligible articles met the inclusion criteria, and they did not fulfill the exclusion criteria (Table 1).

\section{Risk of bias}

Considering the included studies were case reports, which were ranked as level 4 evidence, an 8-item JBI Critical Appraisal Checklist for Case Reports was employed to assess the risk of bias (ROB). If the answers for all the 8 items were YES, this study was appraised as low ROB; otherwise, the ROB was high. The appraisal of the included articles was undertaken independently by $\mathrm{PH}$ and WF. When disagreement occurred between the two appraisal results, they were then discussed and arbitrated by the all authors.

\section{Data collection}

The full text of the included articles was studied. The following information was extracted: (1) clinical features: genders, age, symptomatic presentations (asymptomatic, neurological deficits and/or local pain); (2) imaging features: vertebral segments (cervical, thoracic, lumbar, and/or sacrum), sites of the niduses (intrabony, durabased, and/orintramedullary); (3) systemic involvement: lesions of lymph nodes or other organs; (4) laboratory test results; (5) treatment regimens: wait and watch, surgery, and/or non-surgery therapies; (6) prognosis and therapeutic outcomes. All the data were then transcribed onto an Excel sheet (see Supplementary Table 1). For

\section{Table 1 The inclusion and exclusion criteria of the study}

Inclusion criteria
a. Cases with spinal lesions, whether symptomatic or not
b. Full texts were availed
c. Publication types of research articles and case reports
d.Literature with complete records of patients' demographic
information, clinical and imaging manifestations
e. References of the eligible articles were also screened
Exclusion criteria
a. Articles in non-English languages
b. Reviews, comments, or other articles wherein no cases were recorded
c. Duplicated literature or same cases in different articles 
data not provided in original articles, we left the slots vacant.

\section{Statistical analysis}

Data analyses were performed using IBM SPSS statistics for Windows Version 20 (IBM Corp., Armonk, NY, USA). Lilliefors test, which is an adaptation of the Kolmogorov-Smirnov test, was used to examine whether the data were normally distributed. Data presentation was provided in the forms of percentages, mean \pm standard deviation, or median (quartile range). Two-tailed unpaired Student's $t$ test and two-tailed Pearson's $\chi 2$ test (or Fisher's exact test) were utilized to make a comparison between different groups. Statistical significance was set at 0.05 .

\section{Results}

A total of 62 articles were included in the study, and they contained 69 cases of spinal RDD (Fig. 1 and Supplementary Table 1) [11-72]. These articles were published from 1976 to 2020, and 42 articles (67.7\%, 42/ 62) were published after 2010. Twelve included studies had high ROB [13, 16-18, 31, 34, 46, 48, 49, 53, 56, 57], whilst 50 other studies had low ROB. The cohort included 45 males and 24 females, at a ratio of 1.9/1. The average age was $33.1 \pm 18.3$ years. Follow-up information was documented in 52 cases, and the median period was 12.0 (11.8) months. The median course before consultation and admission was 2.1 (5.0) months (Table 2).

A total of 63 cases $(91.3 \%, 63 / 69)$ manifested spinerelated symptoms. A total of 54 cases $(78.3 \%, 54 / 69)$ suffered from myelopathy or radiculopathy, and 31 cases $(44.9 \%, 31 / 69)$ complained of focal pain in the lesions. Multiple organ involvement was reported in 27 cases $(39.1 \%, 27 / 69)$, and massive lymph nodes were found in 12 cases $(17.4 \%, 12 / 69)$. Abnormal results of laboratory tests, such as elevated white blood cell count, C-reactive protein, and erythrocyte sedimentation rate, were described in 17 cases $(24.6 \%, 17 / 69)$ (Table 2).

The initial symptoms of 47 cases $(68.1 \%, 47 / 69)$ were spine-related; among them, 10 cases $(21.3 \%, 10 / 47)$ were screened for coexisting niduses at other organs by imaging, and 6 cases $(12.8 \%, 6 / 47)$ had lymph node enlargement. Only 3 cases $(6.4 \%, 3 / 47)$ were diagnosed correctly, while the other $93.6 \%$ of cases $(44 / 47)$ were misdiagnosed before postoperative pathological examinations. A total of 22 cases first presented with painless

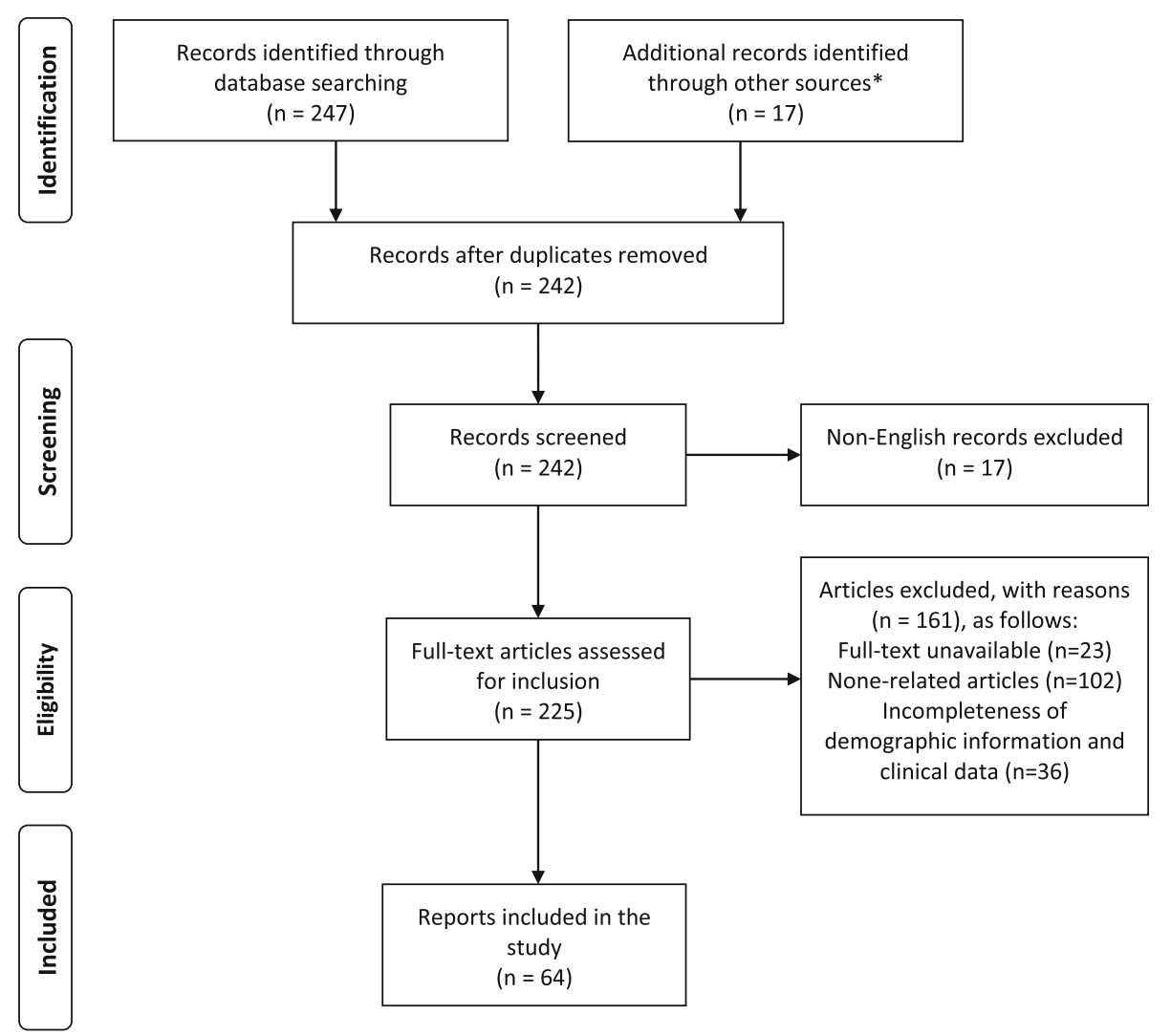

Fig. 1 Flow diagram of the literature search, screening, and inclusion in the present study. *The other source besides the searched databases was references of the included reports 
Table 2 Presentation of basic data of the included spinal Rosai-Dorfman cases $^{\text {a }}$

\begin{tabular}{ll}
\hline Item & Value \\
\hline Age, mean \pm standard deviation & $(33.1 \pm 18.3)$ years \\
Course, M(QR) & $2.1(5.0)$ months \\
Follow-up period, M(QR) & $12.0(11.8)$ months \\
Spine-related symptoms & $63(91.3 \%)$ \\
Focal pain at the spinal lesions & $31(44.9 \%)$ \\
Myelopathy/radiculopathy & $54(78.3 \%)$ \\
Lymph nodes enlargement & $12(17.4 \%)$ \\
Multiple organ involvement & $27(39.1 \%)$ \\
Abnormal laboratory tests & $17(24.6 \%)$ \\
\hline
\end{tabular}

$\mathrm{M}(\mathrm{QR})$ stands for median(quartile range)

${ }^{a}$ Only data that were originally documented were included in this statistical analysis

lymph node enlargement or other organ-related symptoms; among them, 16 cases $(72.7 \%, 16 / 22)$ developed spinal lesions and symptoms afterward.

Imaging work-ups revealed that the lesion manifested T1-weighted isointensity to the cord and T2-weighted slight hyperintensity on MRI scans (Fig. 2a, b). The bony lesions were osteolytic and non-expansile and were located inside cancellous bones (Fig. 2c). PET/CT could reveal multiple organ lesions, which were moderate to high uptake of 18-fluorodeoxyglucose (Fig. 2d).

The lesion sites of spinal RDD were documented in 67 cases; among them, 26 cases $(38.8 \%, 26 / 67)$ developed RDD lesions in the cervical spine and 27 cases $(40.3 \%$, 27/67) developed RDD lesions in the thoracic spine (Table 3). Seven cases $(10.4 \%, 7 / 67)$ had lesions in multiple spinal segments. The nidus sites and lesion bases were described in 62 cases. Intracanal dura-based lesions were found in 39 cases $(62.9 \%, 39 / 62)$, whereas the rates of intramedullary and intrabony lesions were 9.7\% (6/62) and $12.9 \%(8 / 62)$, respectively. Altogether, there were 53 cases $(85.5 \%, 53 / 62)$ with lesions focally constrained to one spinal component, namely bone, dura, or cord parenchyma. A total of 9 cases $(14.5 \%, 9 / 62)$ had focally concurrent lesions invading multiple spinal components, for example, bone and dura (Table 3).

The diagnoses were made based on histopathological and immunochemical examinations in all the included cases, rather than on clinical and imaging manifestations. The histopathological features were histiocytic cells in a fibrous background, with an infiltration of lymphocytes and plasma cells, and emperipolesis of surrounding cells into histiocytic cells. The immunohistochemical phenotype was CD68 and S100 positive and CD1a negative; this phenotype is specific and diagnostic, according to the included reports.

Treatment regimens were reported in 66 cases. A total of 42 cases $(63.6 \%, 42 / 66)$ underwent surgeries, 10 cases $(15.2 \%, 10 / 66)$ received surgeries and adjuvant therapies, and 9 cases $(13.6 \%, 9 / 66)$ received radiotherapy, steroids, and/or chemotherapy without surgeries (Fig. 3). A total of 5 cases $(7.6 \%, 5 / 66)$ received no specific treatment but a wait and watch strategy [17, 46, 48, 64, 69]. Among the 52 cases receiving surgeries, total lesion resection was achieved in 23 cases (44.2\%), and 29 cases (55.8\%) underwent decompression surgeries with or without partial lesion resection.

A total of 54 cases reported follow-up data (Table 4). A total of 44 cases $(81.5 \%, 44 / 54)$ reported no recurrence or stable residual lesions, whereas 10 cases $(19.5 \%$, 10/54) experienced recurrence or progression of spinal lesions. Lesions constrained to the dura, intrabony region, or intramedullary region were correlated with lower recurrence and progression rates than focally

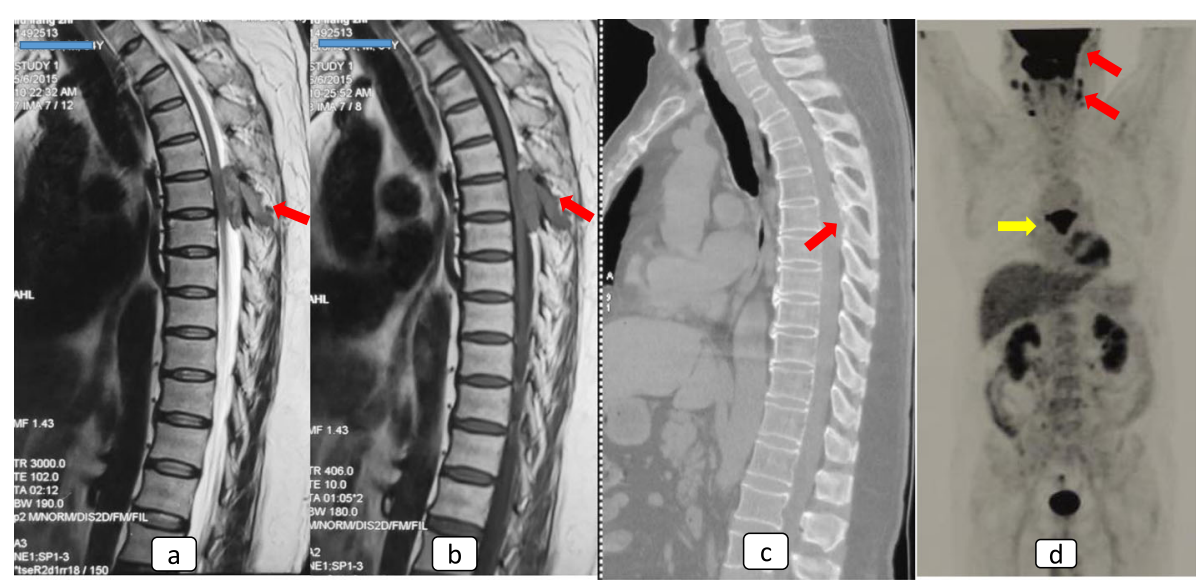

Fig. 2 The imaging presentation of a case with spinal RDD. MRI scans manifested a T1 isointense (a) and T2 slightly hyperintense (b) extradural lesion on Th6. The spinous process was also involved (arrows on $\mathbf{a}$ and $\mathbf{b}$ ). CT scan revealed an osteolytic lesion, but the cortex seemed intact (arrow on c). PET/CT scan was arranged. Paranasal lesions and cervical lymph node lesions were also found and the lesions manifested a high uptake of 18-FDG (red arrows on d) 
Table 3 Summary of lesion sites on spinal segments and lesion bases

\begin{tabular}{|c|c|c|c|c|c|}
\hline \multicolumn{3}{|c|}{ Spinal segments $(n=67)$} & \multicolumn{3}{|c|}{ Lesion bases/origins $(n=62)$} \\
\hline & Count & Percentage & & Count & Percentage \\
\hline Cervical & 26 & $38.80 \%$ & Intramedullary & 6 & $9.70 \%$ \\
\hline Thoracic & 27 & $40.30 \%$ & Intrabony & 8 & $12.90 \%$ \\
\hline Lumbar & 4 & $6.00 \%$ & Dura-based & 39 & $62.90 \%$ \\
\hline Sacrum & 3 & $4.50 \%$ & Concurrent & 9 & $14.50 \%$ \\
\hline Multi-segment lesions & 7 & $10.40 \%$ & & & \\
\hline
\end{tabular}

unconstrained lesions $(p=0.033)$. Patients with systemic multiple lesions had marginally higher recurrence and progression rates than patients with isolated spinal lesions $(p=0.346)$. Among those who underwent surgery, the rate of recurrence/progression was $17.8 \%$ and $22.2 \%$ for non-surgery cases $(p=0.754)$. The recurrence and progression rates for cases after total resection and partial resection were $9.1 \%$ and $26.1 \%$, respectively, with no significant difference $(p=0.243)$. For those who received radiotherapy, steroids, and/or chemotherapy, the recurrence/progression rate was $28.6 \%$ and $15.0 \%$ for the patients who did not receive the above therapies, with no significant difference $(p=0.261)$.

Based on the review and analysis of the data regarding on the clinical symptoms, imaging work-ups, and treatment and their outcomes, a preliminary algorithm was proposed for the diagnosis and treatment of the spinal RDD (Fig. 4).

\section{Discussion}

Spinal RDD poses a great challenge for the diagnosis and treatment due to a lack of mature guidelines in clinical practice. According to our study, $93.6 \%$ of cases whose initial symptoms were spine-related could not be correctly recognized until postoperative pathological examination. Computed tomography (CT)-guided biopsy results were recorded in six cases; three cases $(50.0 \%)$ failed to make a definite and correct diagnosis [17, 24, $31,34,57,62]$. The failure rate was relatively high in the included reports. The possible reasons were the failure to harvest the target specimen and failure to recognize it on cellular smears. The features of cellular smear are not diagnostic and cannot be differentiated from Langerhans cell histiocytosis, reactive lymphadenitis, hemophagocytic syndrome, and malignant lymphoma [24, 57].

Spinal RDD has a predilection for young and middleaged people, with an average age of 33.1 years and $47.8 \%$ (33/69) cases aged between 18 and 45 years. The study noted gender variation with a predominance of males (1.9/ 1). Spinal RDD has no specific and pathognomonic symptoms, although $91.3 \%$ of the included cases manifested spine-relevant symptoms. Previous literature reported that about $80 \%$ RDD patients have painless massive neck or axillary lymphadenopathy $[1,3,19,21]$. However, this study found the records of lymph node enlargement in $17.4 \%$ of cases, which was significantly lower than that in the previous literature (Table 2). It implies that spinal RDD might have some unique pathological features.

\section{Treatment options for the recorded cases $(n=66)$}
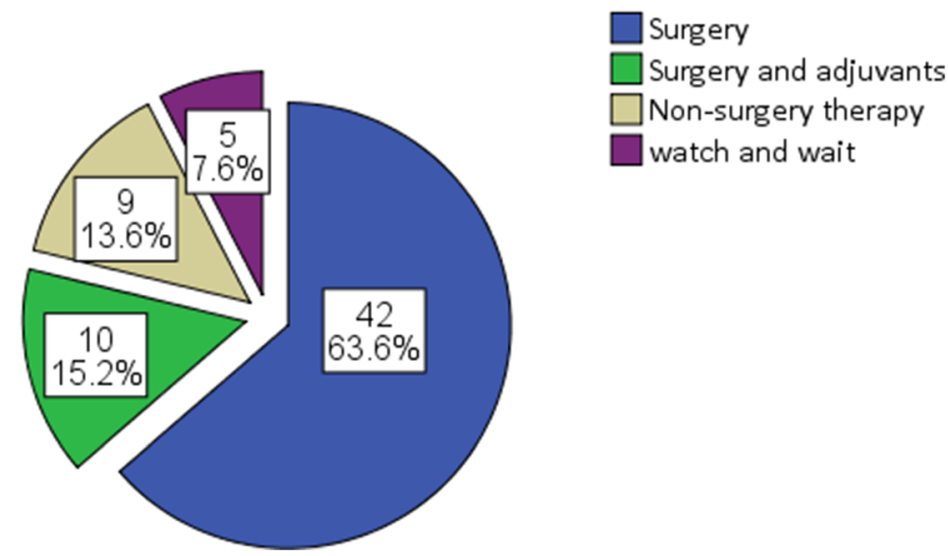
radiotherapy, steroids and chemotherapy 
Table 4 Correlation analysis of lesion recurrence or progression with clinical and therapeutic factors

\begin{tabular}{|c|c|c|c|}
\hline \multirow[t]{2}{*}{ Clinical and therapeutic factors ${ }^{*}$} & \multicolumn{3}{|c|}{ Recurrence and/or progression of spinal lesions } \\
\hline & Yes & No & $p$ value \\
\hline Age $(n=54)$ & $36.2 \pm 21.8$ & $34.1 \pm 18.5$ & 0.758 \\
\hline \multicolumn{4}{|l|}{ Focal lesion conditions $(n=51)$} \\
\hline Focally constrained & $5(11.4 \%)$ & 39(88.6\%) & $0.033^{\#}$ \\
\hline Focally concurrent & $3(42.9 \%)$ & $4(57.1 \%)$ & \\
\hline \multicolumn{4}{|l|}{ Involved organs ( $n=33$ ) } \\
\hline Single & $1(6.7 \%)$ & 14(93.3\%) & 0.346 \\
\hline Multiple & $4(22.2 \%)$ & $14(77.8 \%)$ & \\
\hline \multicolumn{4}{|l|}{ Treatment options $(n=54)$} \\
\hline Surgery & $8(17.8 \%)$ & $37(82.2 \%)$ & 0.754 \\
\hline Non-surgery & $2(22.2 \%)$ & $7(77.8 \%)$ & \\
\hline \multicolumn{4}{|l|}{ Surgical strategies $(n=45)$} \\
\hline Total resection & $2(9.1 \%)$ & $20(90.9 \%)$ & 0.243 \\
\hline Non-total resection & $6(26.1 \%)$ & 17(73.9\%) & \\
\hline \multicolumn{4}{|l|}{ Non-surgery therapies ( $n=54$ ) } \\
\hline Yes & $4(28.6 \%)$ & 10(71.4\%) & 0.261 \\
\hline No & $6(15.0 \%)$ & $34(85.0 \%)$ & \\
\hline
\end{tabular}

Non-surgery therapies include radiotherapy, steroids and/or chemotherapy. Focally constrained lesions mean isolated lesions focally constrained to the dura, intrabony region, or intramedullary region. Focally concurrent lesions mean lesions invading multiple spinal components

*Only data documented in the original literature were included

"Statistically significant at $p<0.05$, two-tailed Pearson's chi-squared test

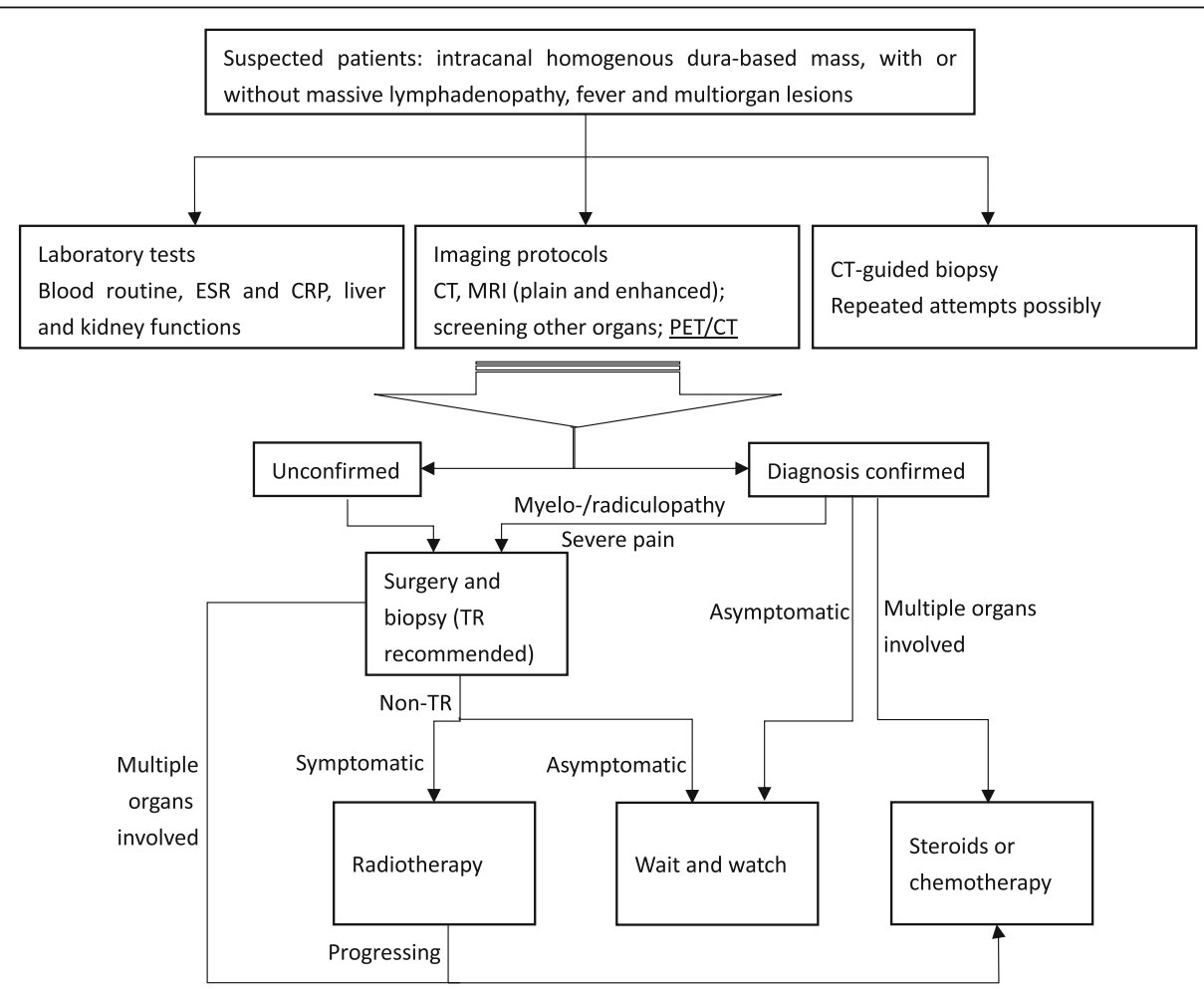

Fig. 4 A preliminarily established diagnosis and treatment algorithm for spinal Rosai-Dorfman disease. ESR stands for erythrocyte sedimentation rate; CRP, C-reactive protein; $C T$, computed tomography; MRI, magnetic resonance imaging; PET/CT, positron emission tomography/computed tomography; TR, total resection 
We found that the lesions mostly occurred in the cervical and thoracic spine (79.1\%) and that $62.9 \%$ of lesions were dura based. The imaging features of RDD are not specific and diagnostic. It is difficult to differentiate this condition from spinal infections, meningioma, lymphoma and other primary or metastatic tumors, chronic inflammation, extradural hematoma, and other histiocytoses, by merely relying on clinical and imaging manifestations.

RDD has a tendency to invade multiple organs [1-3]. We noted reports of deaths due to lesions in other organs [43]. In addition, this study found that the recurrence rate of isolated spinal lesions was marginally lower than that of multi-organ lesions (6.7\% versus $22.2 \%)$. Therefore, it is necessary to screen all possible lesions in other organs when dealing with spinal RDD patients. Mayo clinic reported a consensus on the diagnosis of systemic RDD [3]. It recommended positron emission tomography/computed tomography (PET/CT) to rule out systemic multiple lesions in each patient. PET/CT is helpful to screen whole-body lymph nodes and discover some uncommon and small lesions, for example, paranasal sinuses (Fig. 2d). In the included case series, only four cases had the records of PET/CT. This might explain the significantly lower rate of lymph node enlargement in included case series in this study (Table 2). We also noticed that many included cases presented with rapidly exacerbating myelopathy, and they were asked to undergo urgent cord decompression surgeries, leaving no time for PET/CT. In this setting, we recommend imaging and ultrasonic examinations of vital organs in the intracranial and abdominal cavity.

This study explored the relationship between focal conditions of the lesions and prognosis. We found that focally unconstrained lesions were correlated with a higher recurrence rate (Table 4). Generally, it is difficult to completely resect unconstrained lesions, and residual lesions have a potential for progression and recurrence. More importantly, focal involvement of multiple spinal components implied that these lesions were able to infiltrate through the anatomical septa and possessed stronger aggressiveness. This finding may provide us an important reference when dealing with spinal RDD.

RDD is benign histiocytosis, and some lesions can resolve spontaneously $[47,65]$. Pulsoni et al. reviewed 40 cases of untreated RDD and found $82 \%$ remitted spontaneously [73]. Rittner and colleagues reported a case with multiple whole-body osseous lesions, including the spine, and it was treated with non-steroidal antiinflammation drugs [47]. After 6 months, most of the lesions resolved spontaneously. Therefore, wait and watch is recommended for patients without symptoms and signs of spinal instability and neurological impairment.

However, for symptomatic patients, for whom cord decompression and restoration of spinal stability are indicated, or malignancy cannot be ruled out, surgery is the treatment of choice whenever feasible. Theoretically, total resection is a better choice, considering the tendency of the lesions to recur (Table 4) $[3,14,15,29,30$, $32,43,44,49,51]$. This study found that the recurrence rate of total resection was marginally lower than that of non-total resection (9.1\% versus $26.1 \%)$. Given a longer follow-up period (the median value of the included cases was 12 months, see Supplementary Table 1), we infer that the difference of the recurrence rates between the total and non-total resection groups would be larger and more statistically significant. Therefore, total resection is the recommended option, especially for those isolated, primary spinal RDD lesions. When the lesions are not completely resectable or systemic lesions are present, adjuvant therapies are indicated. Adjuvant therapies mainly include radiotherapy, steroids, and chemotherapy. However, they were not proven beneficial in this study (Table 4). Radiotherapy has provided excellent locoregional control for isolated lesions, but incompetent for extensive systemic involvement. Chemotherapy regimens were usually prescribed based on personal experience rather than high-level evidence, and its efficacy was not verified in the most patients [73]. The efficacy of steroids was not supported in the case series of this study, either, especially for aged ones or patients with multiple organs involvement [11, 14, 31, 44, 45, 62]. Thus, surgical resection, with or without adjuvant therapies, remains as a primary modality for spinal RDD when therapeutic interventions are indicated.

Based on a comprehensive review of the literature on spinal RDD, we established a preliminary workflow for the diagnosis and treatment of this disease, which may provide some assistance to our peers. For patients suspicious of RDD, laboratory tests of inflammatory indexes and imaging work-ups including $\mathrm{CT}$ and MRI are imperative. PET/CT is also strongly recommended, which can rule out systemic lesions and, especially, the involvement of superior lymph nodes. Considering the fact that imaging modalities are not diagnostic, CT-guided biopsy is often necessary. Surgery is the treatment of choice for the patients who present with symptoms of neurological deficits and refractory local pain. Adjuvant therapies, including steroids, chemotherapy, and radiotherapy, are indicated for progressive lesions and patients with systemic involvement. For the patients without neurological deficits and signs of spinal instability, a wait and watch strategy shall be adopted. However, this study found that the rate of lesion recurrence/ progression in the spine was as high as $19.5 \%$, implying that the current treatment strategies for spinal RDD still need to be improved. Thus, high-level clinical research studies are required to eventually build a standard and more effective treatment guideline. 


\section{Limitations}

Firstly, the included literatures in this study were mostly case reports, which were referred to low-quality evidences. This can influence the quality of this study. Secondly, there may be risk of inclusion bias due to searching strategies and the availability to some literature. Thirdly, some of included literature did not have the records of all the data of interest, which might influence statistical analysis and the interpretation of the results.

\section{Conclusions}

The diagnosis and treatment of spinal RDD remain a huge challenge. It has no pathognomonic clinical and imaging features. Most cases initially present with spine-related symptoms. Only a small number of cases have massive lymphadenopathy, fever, and other constitutional symptoms. The lesions have a predilection for the cervical and thoracic spine, and they are mostly dura based. PET/CT is helpful to discover whole-body lesions and can provide some evidence for the diagnosis. Generally, pathological examinations are an exclusive way to make the diagnosis. The rate of recurrence and new occurrence in other vertebrae was as high as $20 \%$; thus, total lesion resection is perceived as the ideal surgical option. Radiotherapy, steroids, and/or chemotherapy are utilized individually or in cases with residual lesions. Some cases can remit spontaneously, so a wait and watch strategy is recommended in patients without symptoms and signs of spinal instability and neurological impairment.

\section{Supplementary Information}

The online version contains supplementary material available at https://doi. org/10.1186/s13643-021-01581-0.

Additional file 1: Supplementary Table 1. Detailed information of the included cases with spinal Rosai-Dorfman disease in this study.

\section{Abbreviations}

RDD: Rosai-Dorfman disease; CT: Computed tomography; PET/CT: Positron emission tomography/computed tomography; FDG: Fluorodeoxyglucose; ESR: Erythrocyte sedimentation rate; CRP: C-reactive protein; MRI: Magnetic resonance imaging; TR: Total resection

\section{Acknowledgements}

We thank LetPub (www.letpub.com) for its linguistic assistance during the preparation of this manuscript.

\section{Authors' contributions}

Conception, P.H., F.W., X.L., and Z.L.; methodology, P.H., F.W., X.L., and Z.L. literature searching, P.H., and F.W.; screening and inclusion, P.H., and F.W.; data extraction and collection, P.H., and F.W., X.L., and Z.L.; statistical analysis, P.H., and F.W.; validation of data and analysis, X.L., and Z.L.; results interpretation, P.H., and F.W., X.L., and Z.L.; writing, P.H., and F.W.; review of writing, X.L., and Z.L.; tables and figures preparation, P.H., and F.W., X.L., and Z.L.; projection administration, F.W. All authors read and approved the final manuscript.

\section{Funding}

None.
Availability of data and materials

We provide all supporting data in Supplementary Table 1.

Ethics approval and consent to participate

Not applicable.

Consent for publication

All authors agree with the publication of this article.

\section{Competing interests}

We have no potential conflicts of interest.

Received: 22 July 2020 Accepted: 2 January 2021

Published online: 18 January 2021

\section{References}

1. Rosai J, Dorfman RF. Sinus histiocytosis with massive lymphadenopathy. A newly recognized benign clinicopathological entity. Arch Pathol. 1969;87: 63-70.

2. Emile JF, Abla O, Fraitag S, Horne A, Haroche J, Donadieu J, et al. Revised classification of histiocytoses and neoplasms of the macrophage-dendritic cell lineages. Blood. 2016;127(22):2672-81

3. Goyal G, Young JR, Koster MJ, Tobin WO, Vassallo R, Ryu JH, et al. Mayo Clinic Histiocytosis Working, G. (2019). The Mayo Clinic Histiocytosis Working Group Consensus Statement for the diagnosis and evaluation of adult patients with histiocytic neoplasms: Erdheim-Chester disease, Langerhans cell histiocytosis, and Rosai-Dorfman disease. Mayo Clin Proc. 2019;94(10): 2054-71.

4. Nathan B, Roomallah B, Salisbury JR, Tenant-Flowers M, Kassam S. A rare cause of lymphadenopathy - Rosai-Dorfman disease in a HIV-positive Ugandan woman. Int J STD AIDS. 2016;27(12):1123-5.

5. Yao JD, McCullough AE, Walker RC, Banks PM. Brucellosis and sinus histiocytosis with massive lymphadenopathy. Am J Med. 1989;86(1):111-4.

6. Luppi M, Barozzi P, Garber R, Maiorana A, Bonacorsi G, Artusi T, et al. Expression of human herpesvirus- 6 antigens in benign and malignant lymphoproliferative diseases. Am J Pathol. 1998:153(3):815-23.

7. Richardson TE, Wachsmann M, Oliver D, Abedin Z, Ye D, Burns DK, et al. BRAF mutation leading to central nervous system rosai-dorfman disease. Ann Neurol. 2018;84(1):147-52.

8. Morgan NV, Morris MR, Cangul H, Gleeson D, Straatman-Iwanowska A, Davies N, et al. Mutations in SLC29A3, encoding an equilibrative nucleoside transporter ENT3, cause a familial histiocytosis syndrome (Faisalabad histiocytosis) and familial Rosai-Dorfman disease. PLoS Genet. 2010;6(2): e1000833.

9. Adeleye AO, Amir G, Fraifeld S, Shoshan Y, Umansky F, Spektor S. Diagnosis and management of Rosai-Dorfman disease involving the central nervous system. Neurol Res. 2010;32(6):572-8.

10. Foucar E, Rosai J, Dorfman RF, Brynes RK. The neurologic manifestations of sinus histiocytosis with massive lymphadenopathy. Neurology. 1982;32(4): 365-72.

11. Sandoval-Sus JD, Sandoval-Leon AC, Chapman JR, Velazquez-Vega J, Borja MJ, Rosenberg S, et al. Rosai-Dorfman disease of the central nervous system: report of 6 cases and review of the literature. Medicine. 2014;93(3):165-75.

12. Purav P, Ganapathy K, Mallikarjuna VS, Annapurneswari S, Kalyanaraman S, Reginald J, et al. Rosai-Dorfman disease of the central nervous system. J ClinNeurosci. 2005;12(6):656-9.

13. Baassiri W, Moussalem CK, Massaad E, Zeidan YH, Darwish H. Craniocervical Rosai-Dorfman disease involving the vertebral artery: case report and literature review. World Neurosurg. 2020;133:69-73.

14. Qin G, Ye J, Lan S, Liang Y, Xu P, Tang X, et al. Rosai-Dorfman disease with spinal and multiple intracranial involvement: a case report and literature review. Br J Neurosurg. 2019:1-5.

15. Lin CK, Tsai YD. Nonresectable thoracic Rosai-Dorfman Disease: a case report and review of the literature. World neurosurg. 2019;132:309-13.

16. Kumaran SP, Thippeswamy PB, Reddy BN, Neelakantan S, Viswamitra S. An institutional review of tuberculosis spine mimics on MR imaging: cases of mistaken identity. Neurol India. 2019;67(6):1408-18.

17. Kong Z, Wang Y, Ma W, Cheng X. FDG PET/CT Image for a Rosai-Dorfman disease with pituitary and bone involvement in a pediatric patient. ClinNucl Med. 2019;44(11):873-5. 
18. Joshi SS, Joshi S, Muzumdar G, Turel KE, Shah RM, Ammbulkar I, et al. Cranio-spinal RosaiDorfman disease: case series and literature review. $\mathrm{Br} J$ Neurosurg. 2019;33(2):176-83.

19. Li Y, Wang X, Gao J, Yu S, Li Z. Isolated extradural Rosai-Dorfman disease causing the spinal cord compression: A case report. Medicine. 2018;97(40): e12722.

20. Chhabria BA, Nampoothiri RV. A quintessential syndrome with a rare marvellingaetiology: Rosai-Dorfman disease presenting as Conus-Cauda syndrome. BMJ Case Rep. 2018;2018:bcr-2017-222398.

21. Xu H, Zhang F, Lu F, Jiang J. Spinal Rosai-Dorfman disease: case report and literature review. Eur Spine J. 2017;26(Suppl 1):117-27.

22. Karthigeyan M, Salunke P, Gupta K, Singh A, Rajasekhar R. Frozen section can "sharpen" or "sand off" the surgeon's knife: 2 case illustrations with skull base meningioma mimics. World Neurosurg. 2017;107:1051.e1-6.

23. Carrasco-Garcia de Leon S, Flores Barragan JM, ReleaCalatayud F, Balcazar Rojas O. Extra-axial mass in the foramen magnum causing cervical compressive myelopathy as a complication of Rosai-Dorfman disease. J ClinNeurol. 2017;13(3):312-4.

24. Tu J, Li WT, Yang C. Rosai-Dorfman disease of the subdural spine with a long segment lesion: A case report and literature review. J Int Med Res. 2017:45(2):875-81.

25. Tripathi R, Serajee F, Jiang H, Huq A. Novel presentation of Rosai-Dorfman histiocytosis with a prolonged course of cranial and peripheral neuropathies. PediatrNeurol. 2017;71:70-2.

26. Rocha-Maguey J, Felix-Torrontegui JA, Cabrera-Lopez M, Gutierrez-Castro M, Montante-Montes de Oca D. A new case of cervical intramedullary sinus histiocytosis causing paraplegia and review of the literature. SurgNeurollnt. 2016;7:9.

27. Igrutinovic Z, Medovic R, Markovic S, Kostic G, Raskovic Z, TanaskovicNestorovic J, et al. Rosai-Dorfman disease of vertebra: case report and literature review. Turk J Pediatr. 2016;58(5):566-71.

28. Huang BY, Zhang H, Zong WJ, Sun YH. Rosai-Dorfman disease of rare isolated spinal involvement: report of 4 cases and literature review. World Neurosurg. 2016;85:367.e11-6.

29. Huang BY, Liu HL, Yu CJ. Isolated Intramedullary Spinal Rosai-Dorfman Disease: A Case Report and Literature Review. World Neurosurg. 2016;88: 694.e11-5.

30. de Oliveira Lima GL, da Costa AC, de Paula Goes BH, Junior NP. Double compression caused by isolated spinal Rosai-Dorfman disease. Spine J. 2016; 16(8):e521-2.

31. Sciacca S, Barkas K, Heptinstall L, McNamara C, Shetty R. Rosai-Dorfman disease with spinal cord compression: a diagnostic challenge. Eur Spine J. 2015:24(Suppl 4):S529-35.

32. Fu X, Jiang JH, Tian XY, Li Z. Isolated spinal Rosai-Dorfman disease misdiagnosed as lymphoplasmacyte-rich meningioma by intraoperative histological examination. Brain Tumor Pathol. 2015;32(1):72-5.

33. Tian Y, Wang J, Li M, Lin S, Wang G, Wu Z, et al. Rosai-Dorfman disease involving the central nervous system: seven cases from one institute. ActaNeurochir (Wien). 2015;157(9):1565-71.

34. Mannelli L, Monti S, Love JE, Kussick SJ, McLuen A, Behnia F. Primary RosaiDorfman disease of the bone in a patient with history of breast cancer: appearance on 99mTc-MDP scintigraphy, CT, and X-ray. ClinNucl Med. 2015; 40(3):247-9.

35. Kozak B, Talbott J, Uzelac A, Rehani B. Rosai-Dorfman Disease Isolated to the Thoracic Epidural Spine. J Radiol Case Rep. 2015;9(11):6-16.

36. $W u$ L, Xu Y. Rosai-Dorfman disease: a rare lesion with dura tail sign mimicking spinal meningioma. Spine J. 2014;14(12):3058-9.

37. Kim DY, Park JH, Shin DA, Yi S, Ha Y, Yoon DH, et al. Rosai-dorfman disease in thoracic spine: a rare case of compression fracture. Korean J Spine. 2014; 11(3):198-201.

38. El Molla M, Mahasneh T, Holmes SE, Al-Khawaja D. Rare presentation of Rosai-Dorfman disease mimicking a cervical intramedullary spinal cord tumor. World Neurosurg. 2014;81(2):442.e7-9.

39. Parmar V, Seward C, Huho A, Qian J, Gandhi R, Pilitsis JG. Rosai-Dorfman disease presenting as cervical radiculopathy. ClinNeurolNeurosurg. 2013; 115(6):808-10.

40. Zhu F, Zhang JT, Xing XW, Wang DJ, Zhu RY, Zhang Q, et al. RosaiDorfman disease: a retrospective analysis of 13 cases. Am J Med Sci. 2013;345(3):200-10

41. Yao K, Li TF, Zhu MW, Duan ZJ, Hu ZL, Bian Y, et al. An intramedullary cervical cord lesion in a 12-year-old girl. Neuropathology. 2013;33(5):582-5.
42. Roy C, Saha A, Roy S, Ghosh A. ExtranodalRosai-Dorfman disease presenting as spinal extradural lesion: a case report with a review of the literature. J Cancer Res Ther. 2012;8(4):647-9.

43. Chen CW, Kachramanoglou C, Revesz T, Choi D. Rosai-Dorfman disease presenting as a thoracic intradural extramedullary spinal tumor but without extraspinal manifestations. ActaNeurochir (Wien). 2012;154(2):367-8.

44. Antuna Ramos A, Alvarez Vega MA, Alles JV, Antuna Garcia MJ, Meilan MA. Multiple involvement of the central nervous system in Rosai-Dorfman disease. PediatrNeurol. 2012;46(1):54-6.

45. Warrier R, Chauhan A, Jewan Y, Bansal S, Craver R. Rosai-Dorfman disease with central nervous system involvement. ClinAdvHematolOncol. 2012;10(3):196-8.

46. Zhu H, Qiu LH, Dou YF, Wu JS, Zhong P, Jiang CC, et al. Imaging characteristics of Rosai-Dorfman disease in the central nervous system. Eur J Radiol. 2012:81(6):1265-72.

47. Rittner RE, Baumann U, Laenger F, Hartung D, Rosenthal H, Hueper K. Whole-body diffusion-weighted MRI in a case of Rosai-Dorfman disease with exclusive multifocal skeletal involvement. Skelet Radiol. 2012;41(6):70913.nguez-Baez JJ.

48. Raslan OA, Schellingerhout D, Fuller GN, Ketonen LM. Rosai-Dorfman disease in neuroradiology: imaging findings in a series of 10 patients. AJR Am J Roentgenol. 2011;196(2):W187-93.

49. Ambekar S, Somanna S, Bhat DI, Ranjan M. Isolated cranio-spinal involvement of Rosai-Dorfman disease: case report. Br J Neurosurg. 2011; 25(2):297-9.

50. Maiti TK, Gangadharan J, Mahadevan A, Arivazhagan A, Chandramouli BA, Shankar SK. Rosai-Dorfman disease presenting as cervical extradural lesion: a case report with review of literature. Neurol India. 2011;59(3):438-42.

51. Wang Y, Gao X, Tang W, Jiang C. Rosai-Dorfman disease isolated to the central nervous system: a report of six cases. Neuropathology. 2010; 30(2):154-8

52. Abou-Zeid AH, Herwadkar A, du Plessis D, Gnanalingham KK. Isolated extradural Rosai-Dorfman disease of the thoracic spine: a rare cause of spinal cord compression: case report. Neurosurgery. 2010;67(2):E514-5.

53. Deng XW, Xie XB, Ye YQ, et al. Intracranial Rosai-Dorfman disease: case report and literature review. European J Radiol Extra. 2010;76:e75-8.

54. Konca C, Ozkurt ZN, Deger M, Aki Z, Yagci M. Extranodal multifocal RosaiDorfman disease: response to 2-chlorodeoxyadenosine treatment. Int J Hematol. 2009;89(1):58-62

55. Raslan O, Ketonen LM, Fuller GN, Schellingerhout D. Intracranial RosaiDorfman disease with relapsing spinal lesions. J ClinOncol. 2008;26(18): 3087-9.

56. Gupta P, Babyn P. Sinus histiocytosis with massive lymphadenopathy (RosaiDorfman disease): a clinicoradiological profile of three cases including two with skeletal disease. PediatrRadiol. 2008;38(7):721-8; quiz 821-2.

57. Jing $X, M c H u g h ~ J B, P u ~ R T$. Fine-needle aspiration cytology of Rosai-Dorfman disease of bone. DiagnCytopathol. 2008;36(7):516-8.

58. Dran G, Rasendrarijao D, Vandenbos F, Paquis P. Rosai-Dorfman disease causing spinal cord compression: case report. Neurosurgery. 2008:62(4): E977-8; discussion E8.

59. Huang YC, Tan HY, Jung SM, Chuang WY, Chuang CC, Hsu PW, et al. Spinal epidural Rosai-Dorfman disease preceding by relapsing uveitis: a case report with literature review. Spinal Cord. 2007:45(9):641-4.

60. Seyednejad F, Tubbs RS, Shoja MM, Daghigi MH, Oakes WJ. Presumed recurrence of intracranial Rosai-Dorfman disease as a cervical spine tumor. ActaNeurochir (Wien). 2007;149(4):425-7.

61. Hargett C, Bassett T. Atypical presentation of sinus histiocytosis with massive lymphadenopathy as an epidural spinal cord tumor: a case presentation and literature review. J Spinal Disord Tech. 2005;18(2): $193-6$.

62. Tubbs RS, Kelly DR, Mroczek-Musulman EC, Hammers YA, Berkow RL, Oakes WJ, et al. Spinal cord compression as a result of Rosai-Dorfman disease of the upper cervical spine in a child. Childs NervSyst. 2005; 21(11):951-4.

63. Chen KT. Crush cytology of Rosai-Dorfman disease of the central nervous system. A report of 2 cases. ActaCytol. 2003;47(6):1111-5.

64. Yip CC, Cheng CL, Poh WT, Choo CT. Orbital, adnexal, and unusual systemic involvement in Rosai-Dorfman disease. Ophthalmic PlastReconstrSurg. 2002; 18(3):223-7.

65. Wu M, Anderson AE, Kahn LB. A report of intracranial Rosai-Dorfman disease with literature review. Ann DiagnPathol. 2001;5(2):96-102. 
66. Andriko JA, Morrison A, Colegial CH, Davis BJ, Jones RV. Rosai-Dorfman disease isolated to the central nervous system: a report of 11 cases. Mod Pathol. 2001;14(3):172-8.

67. Hollowell JP, Wolfla CE, Shah NC, Mark LP, Whittaker MH. Rosai-Dorman disease causing cervical myelopathy. Spine (Phila Pa 1976). 2000;25(11): $1453-6$.

68. Kelly WF, Bradey N, Scoones D. Rosai-Dorfman disease presenting as a pituitary tumour. ClinEndocrinol (Oxf). 1999;50(1):133-7.

69. Katz DS, Poe LB, Corona RJ Jr. Sinus histiocytosis with massive lymphadenopathy: a case of simultaneous upper respiratory tract and CNS disease without lymphadenopathy. AJNR Am J Neuroradiol. 1993;14(1):219-22.

70. Unni KK. Case report 457. Sinus histiocytosis with massive lymphadenopathy (Rosai-Dorfman disease) presenting as lesion in the sacrum. Skelet Radiol. 1988;17(2):129-32.

71. Haas RJ, Helmig MS, Prechtel K. Sinus histiocytosis with massive lymphadenopathy and paraparesis: remission with chemotherapy. A case report. Cancer. 1978:42(1):77-80.

72. Kessler E, Srulijes C, Toledo E, Shalit M. Sinus histiocytosis with massive lymphadenopathy and spinal epidural involvement: a case report and review of the literature. Cancer. 1976;38(4):1614-8.

73. Pulsoni A, Anghel G, Falcucci P, Matera R, et al. Treatment of sinus histiocytosis with massive lymphadenopathy (Rosai-Dorfman disease): report of a case and literature review. Am J Hematol. 2002;69(1):67-71.

\section{Publisher's Note}

Springer Nature remains neutral with regard to jurisdictional claims in published maps and institutional affiliations.

Ready to submit your research? Choose BMC and benefit from:

- fast, convenient online submission

- thorough peer review by experienced researchers in your field

- rapid publication on acceptance

- support for research data, including large and complex data types

- gold Open Access which fosters wider collaboration and increased citations

- maximum visibility for your research: over $100 \mathrm{M}$ website views per year

At BMC, research is always in progress.

Learn more biomedcentral.com/submissions 